\title{
Teaching Practice and Research on BIM-Based Assembled Building Measurement and Valuation
}

\author{
Jiandong Tian* Guifang He \\ School of Construction and Engineering, Hezhou University 524800, China
}

\begin{abstract}
As the construction industry and information technology are being deeply integrated, it is of great practical significance to rapidly develop the practical training course Measurement and Valuation of Prefabricated Construction based on building information modeling (BIM). In this paper, we comprehensively analyze the status quo of teaching of the course Measurement and Valuation of Prefabricated Construction in China as well as the existing problems about the BIM-integrated teaching. Further, we take into account four aspects as per the talent training program: course system setup, syllabus development, teacher team building, and construction of a BIM-based construction cost practice base. Then, we put forward a teaching reform mode of the course Measurement and Valuation of Prefabricated Construction, namely a new "five-in-one" teaching mode, which matches new technology and adapts to the transformation and upgrading of China's construction industry. We perform a teaching reform in the BIM-based practical training course Measurement and Valuation of Prefabricated Construction for construction cost majors in School of Construction and Engineering at a Guangxi university. This reform is fruitful and provides a theoretical reference for carrying out the similar reform across China.
\end{abstract}

Keywords: prefabricated construction; measurement and valuation course; BIM; teaching practice and research DOI: $10.7176 / \mathrm{JEP} / 10-27-01$

Publication date:September $30^{\text {th }} 2019$

\section{Introduction}

As China's construction industry undergoes transformation and upgrade, industrialized prefabrication has gradually replaced the traditional mode of construction. Therefore, courses on the measurement and valuation of construction engineering corresponding to the traditional mode of construction fail to appropriately train application-oriented technical personnel majoring in cost of construction in this new era. The course on the measurement and valuation of prefabricated construction is a core course for construction cost majors. It is also important for teachers offering specialized courses in the area.

In recent years, many domestic and foreign researchers have studied teaching reforms in courses on the measurement and valuation of prefabricated construction. Lin et al. studied major problems in standard practice that affect quality inspection in construction data management, including lengthy procedures, redundant data input, and chaotic and inefficient information management, and proposed a practical method to apply BIM to quality inspection and defect management. Research has shown that the integration of BIM into network technology contributes to an effective visual defect management platform that improves the efficiency of defect management of on-site quality engineers and managers, and ensures the quality of the construction products (Lin, et.al, 2017). He et al. noted that BIM, as a new technology in construction, was already widely used in Europe and America owing to its low cost, high efficiency, visualization, and data sharing. To solve the problem of a lack of construction and engineering professionals who have mastered BIM, the Harbin Institute of Technology has offered a course civil engineering drawing for construction and engineering majors. The results of two rounds of teaching show that the introduction of three-dimensional (3D) teaching can help improve students' ability to read civil drawings and stimulate their interest in active learning(He, et.al, 2017). Wang et al. claimed that the course is an important way for colleges and universities to train students. Once the course teaching plan and course system have been improved, and advanced concepts and methods of teaching have been introduced, students can develop learning ability, practical ability, innovative ability, and a spirit of exploration (Wan, et.al, 2017). Mehmet et al. claimed that facility management includes a variety of operations, activities, and maintenance services, and supports the main functions of an in-use building or facility. It requires comprehensive information about the facility. They noted that BIM features the advantages of visualization, interoperability, and information exchange, and BIM-integrated facility management can thus simplify frequency modulation (FM) activities. Through case studies, they also proved the value-added potential of BIM and its advantages for facility management. They also evaluated potential challenges that hinder the effective use of BIM in FM (Mehmet, et.al, 2014). Yang et al. proposed that internationalization is an important trend in today's engineering education. As a result, the teaching of a certain course should also adapt to the need for talent development in such a context. In response to education internationalization, they conducted a systematic teaching reform in a postgraduate course for chemical engineering majors, including updating and improving the syllabus, teaching content, teaching method, and grading. They proposed ideas and specific practices to benefit other higher education practitioners 
(Yang, et.al, 2017). Liu claimed that the course on the measurement and valuation of construction engineering is the core course for construction cost and construction supervision majors in vocational colleges. The main objective of the course is to enable students to understand and master the basis and methods of construction measurement and valuation so that they can analyze, determine, and control construction costs, and provide construction cost consultation services (Liu, 2014). Fang et al. claimed that the course is fundamental for training application-oriented construction cost professionals. They studied the characteristics and current situation of the course, and proposed a reform plan for it that has certain reference significance for training application-oriented construction cost professionals (Fang, et.al, 2014). However, prefabricated construction involves both prefabrication and cast in place. The construction drawings of different design organizations are not identical in terms of construction technology, especially in joint treatment. Specifically, some organizations apply grout sleeves while others use cast-in-place concrete. These differences pose significant challenges for the establishment of BIM for the measurement and valuation of prefabricated construction. To make students proficient in this, we propose integrating BIM into the daily teaching of the course on the measurement and valuation of prefabricated construction. To this end, we propose a five-in-one teaching mode of "teaching, learning, practice, discussion, and practice" to realize a combination of theory and practice in teaching. This is important for teaching practice and research on the BIM-based practical training course on the measurement and valuation of prefabricated construction.

\section{Materials and methods}

\subsection{Status quo of the teaching of measurement and valuation of construction engineering in colleges and universities and its integration into BIM}

Most colleges and universities offer courses on the measurement and valuation of construction engineering but on those of prefabricated construction. When teaching the former course, the teacher applies the traditional mode of teaching, which is to say that he or she presents the theory in class and then asks students to carry out practical operations in the BIM laboratory at the end of the course. This leads to the below problems with the quality of teaching.

(1) Highly theoretical but relatively impractical content of the textbook and bad regional adaptability.

The course on the measurement and valuation of construction engineering is a practical course with important political, systematic, and professional elements. Changes in national policies and norms are relatively rapid, whereas most textbooks on the subject are compiled by colleges and universities themselves. The levels of instruction of these textbooks are different, the content is updated late, and the timeliness and regional characteristics of these texts are obvious (Wu, et.al, 2015). Most such textbooks focus on theoretical knowledge. Even though some features practical operations, computer-based practice is often carried out once the teacher has finished teaching the entire course. Usually, the teacher presents pre-packaged points and his/her own opinions in class, and the students learn by rote. It thus becomes difficult for them to fully understand the essential content of the course and master practical capabilities. No organization in China to date has published an applicationoriented textbook that features prefabricated construction and completely meets the teaching needs of colleges and universities.

(2) Lack of teachers with practical experience.

Because the course on the measurement and valuation of prefabricated construction includes content on prefabricated construction and cast-in-place concrete, the teacher is required to have good command of traditional modes of construction measurement and valuation, the measurement and valuation of prefabricated construction, and the application of BIM to the latter. In addition, the teacher must not only have a solid theoretical foundation, but also have impressive practical ability to solve various problems that arise during operation. However, most teachers possess highly theoretical knowledge but seldom practice outside the school. They cannot operate BIM software skillfully or accurately, which makes it difficult to arouse students' interest in the course. The course on the measurement and valuation of prefabricated construction is designed to the application-oriented technical personnel but theoretically adept teachers usually cannot do this. This is to say that the students they cultivate have a solid theoretical foundation but poor skills of practical operation, and are at a disadvantage in the industry. Therefore, it is pivotal to train teachers with practical experience (Liu, 2017).

(3) A simple method of assessment and a closed-book exam on theoretical knowledge.

The course on the measurement and valuation of prefabricated construction requires students to master a solid theoretical foundation and a practical ability. However, most colleges and universities still examine students in these courses through paper-based tests. The assessment aims simply at testing students' grasp of certain knowledge. The final result is given by combining the paper test and the results of performance in class, or by assessing a course-related essay. These methods cannot enable students to effectively grasp the relevant knowledge, and nor can it motivate their interest in the course (Wang, 2016). In view of this, students can fully grasp the knowledge and skills for the course only by experimenting in a BIM laboratory and applying a strict theoretical and practical method of operational assessment. 
(4) Separation of theoretical teaching in class from practical training.

The course on the measurement and valuation of prefabricated construction is highly practice oriented, and requires that students combine knowledge with practical skill. In this way, application-oriented technical personnel needed to estimate the cost of construction can be trained. In recent years, the Ministry of Education of the People's Republic of China has promoted teaching reform and proactively organized activities for college students to improve their ability to innovate and apply their knowledge. At the same time, colleges and universities have formulated talent training programs for undergraduates, offered practical training courses, and tried to provide practical training bases or internships for students. These measures have achieved some success and led to a group of skilled students (Fan, et.al, 2017). However, some of the practical activities initiated are not closely related to the course, and the ones that are last no more than 16 class hours, which is a relatively short time. This makes it challenging for students to apply knowledge learned in class flexibly to practical activities.

(5) The modern teaching mode is completely separated from the traditional teaching mode and has no advantages of inheriting the traditional teaching mode.

At present, in some schools, due to the relatively high maintenance cost of BIM laboratories and the complicated procedures for teachers to apply for BIM laboratories, the use frequency of BIM laboratories is limited to a certain extent. Students are extremely excited about taking BIM experimental classes. They may only bring one book in class, listen to the teachers and watch the teachers do it. As a result, BIM experimental classes become pure entertainment for them, lacking the awareness of active learning and active recording. After a long period of research, it is shown that taking notes can not only control students' attention and promote students' understanding of knowledge, but also help students to discover the connection between old and new knowledge. In addition, because the computer screen display speed is too fast, students have no time to think, discuss and record, or the computer screen display is too early, students may not have time to think and discuss, BIM model has been built and displayed, and students have no interest in thinking, discussing and recording (Ma, et.al, 2015). It is also because of the fast speed and large capacity of computer teaching, coupled with the lack of interaction between teachers and students, the lack of immediate feedback in the classroom, the new knowledge is difficult to keep in the minds of students.

\section{Results}

\subsection{A "five-in-one" teaching mode based on BIM}

BIM is the abbreviation of the English letter Building Information Modeling. It refers to the general name of the process and results of design, construction, operation and maintenance based on the digital expression of physical and functional characteristics in the whole life cycle of building engineering or building facilities (Azhar, et.al, 2012). It is referred to as building information model. BIM is a multi-dimensional information integration model, which enables all participating units of a construction project, including construction administrative departments, construction units, design units, construction units, supervision units, engineering cost consulting units, operation and maintenance property management units, project use units, etc., to add information to the model and operate the model in the information throughout the life cycle of the project from conceptual design to complete dismantling (Miettinen, et.al, 2014). Fundamentally change the way engineers and technicians rely on drawings in the form of symbols and characters to carry out project construction and operation management, so as to achieve the goals of improving work efficiency and quality, reducing design errors and controlling construction risks in the whole life cycle of construction projects. It is a real-time shared data platform for construction projects, which can solve the problems of relevance between distributed and heterogeneous engineering data and global information sharing, and support the dynamic construction engineering information creation, management and sharing in the whole life cycle of construction projects (Demian, et.al, 2014).

The word "mode" in teaching mode comes from English "Model", which can also be translated into "model" and "normal form". Generally speaking, it refers to the theoretical logical framework of the object to be studied. Mode is an operable knowledge system between experience and theory and a theoretical simplified structure that reproduces reality $(\mathrm{Li}, 2017)$. The "teaching mode" was first put forward by Joyce (B. Joyce) and Well (M. Well) and others in the "teaching mode" in the United States, and pointed out that the "teaching mode" is a paradigm or plan that constitutes courses and homework, selects teaching materials and prompts teachers' activities. Joyce and Weil etc. have integrated the model into the teaching theory to illustrate the basic structure or framework of various types of teaching activities established under the guidance of certain teaching theories and the procedural strategy system to show the teaching process (Wang, 2018). The "five-in-one" teaching mode refers to the teacher's use of multimedia to assist classroom teaching. According to the teaching task, subject characteristics and students' learning reality, the teacher grasps the teaching focus, breaks through the teaching difficulties, and reasonably combines the five basic teaching links of "teaching, learning, practice, discussion and re-practice" to better play the main role of students and the leading role of teachers, to realize the best combination of teaching activities and the optimization of teaching process, to fully embody the advantages of 
multimedia-assisted teaching, and to truly realize the informatization and modernization of education, so as to construct a teaching structure with both the leading and the main role, and to comprehensively improve the classroom teaching efficiency (Cun, 2017).

The BIM-based practical training course on the measurement and valuation of prefabricated construction uses a new "five-in-one" teaching mode of "teaching, learning, practice, discussion, and practice," and requires that teachers have a solid theoretical background, rich practical experience, and the ability to flexibly solve practical problems (Zhou, et.al, 2015). The entire teaching process is conducted in the BIM laboratory, and the new "five-in-one" teaching mode allows for the full integration of theoretical knowledge into learning. When teaching each chapter of a given textbook to students, the teacher first presents the theoretical knowledge and then provides practical examples. Further, the student imitates the teacher in carrying out operations. This can inspire students to think and train hands on (Wang, et.al, 2016). They can also discuss and communicate directly with the teacher through the "electronic hands up" function on the computer. Once the course ends, the teacher arranges for students to complete practical projects to reinforce their mastery of the course. Through repeated hands-on experience, students can master the skills required, which is the goal of this teaching reform (Qian, 2016).

(1) Rapidly promoting the construction of a BIM-based construction cost practice base.

To develop application-based technical personnel, we need to consider specialized course teaching reform that combines theories and practice, offer BIM-based practical training courses on the measurement and valuation of prefabricated construction for construction cost majors, and build a BIM-based construction cost practice base. The latter can be created by the school or through industry-university collaboration to provide a strong guarantee of practical teaching. Through the construction of the internal BIM-based construction cost practice base, theoretical knowledge and practical training can be seamlessly integrated, and teaching and production are closely combined. In addition, BIM-based construction cost practice base is open to the public, and is built into an open and shared vocational skill training base. This base provides a place for the school to train application-oriented talents and offers an excellent training site to assess the vocational skills of local professionals. It also expands the range and target of services (Cai, 2017).

(2) Strengthening teachers' team-building and recruiting teachers with practical experience.

Most teachers of measurement and valuation of prefabricated construction are theoreticians who lack practical experience. It is thus difficult to train construction cost personnel who can meet the current needs of the industry. Therefore, colleges and universities should apply a series of methods and measures, recruit teachers with practical experience, and adjust the faculty structure in their construction cost departments. In this way, theory and practical teaching can be best combined, which is key to reforming the teaching of modern specialized courses. Specifically, colleges and universities can arrange for their outstanding teachers to temporarily engage in consulting enterprises in construction and construction cost for six months to a year. In this way, the school can independently train teachers with both theoretical and practical knowledge. In addition, the school can employ construction cost professionals with rich practical experience as full-time teachers. This can help quickly increase the size of the team of trained teachers and who can teach students the practical skills they currently lack. The implementation of these two measures can provide a solid foundation for the new "fivein-one" teaching mode based on BIM (Luo, et.al, 2017).

(3) Setting-up BIM-based course on the measurement and valuation of prefabricated construction.

First, the teacher should introduce the basic concepts of construction cost and project quotas, the bill of quantities (BQ) and its preparation, and basic knowledge concerning BIM. Second, the teacher should present the measurement of construction engineering and prefabricated construction, including the measurement of the building area, the amounts of construction materials, prefabricated concrete, prefabricated steel, and prefabricated timber, the number of building units and parts, the materials needed for decoration, and valuation with a BQ. The teacher should also introduce the method of measurement of the number of items of a BQ and provide training examples. Finally, the teacher should carry out a case study on the measurement and valuation of prefabricated construction composed of two parts: BIM-based tender control price for prefabricated civil construction work, and the BIM-based measurement of prefabricated steel construction work. The teacher should teach the course in the BIM laboratory by using a multimedia networking system. This can help achieve the synchronous interactive control of "teaching, learning, doing," and can improve the efficiency of teaching (Zhu, et.al, 2015).

(4) Formulating syllabus for BIM-based course.

Because prefabricated construction covers both prefabrication and general construction, construction cost personnel are required to learn the measurement and valuation of both, and to master the basic concepts of construction cost, project quota, and BQ and its preparation. The application of BIM makes the measurement and valuation of prefabricated construction efficient, accurate, and intuitive. Therefore, it is important to master the basic knowledge of BIM. For the measurement of the general construction quantity, students are required to master the method of measuring the BQ, and skillfully use BIM software to model and measure it. For the 
measurement of the material for prefabricated construction, they are required to understand the method of measuring the number of prefabricated building unit installations, for which they need to be proficient at BIM software to model and measure them. To measure of the materials needed for decoration and the ceiling, they are required to be skilled in using BIM software to model and measure them. The same applies to materials for steel construction and preparing the tender control price for prefabricated civil construction.

(5) Creating a teaching plan, and improving teaching procedures and assessment systems.

At the beginning of each semester, the school should require teachers to submit a thorough teaching plan according to the training program for construction cost undergraduates, and should strictly control each procedure of the course on the measurement and valuation of prefabricated construction when formulating the plan. Before taking this course, students should take the courses on engineering drawing and knowledge maps, building tectonics, and the design of construction organization. Regarding the order of learning procedures, students should first learn the basic knowledge of construction cost, project quota, BIM, and BQ and its preparation, and then learn methods of measuring materials for construction engineering and prefabricated construction. In this way, they can accomplish the general objectives of the course. In addition, a good assessment system can effectively improve students' interest in learning and their learning efficiency. The school can motivate students by further improving the assessment system. The assessment criteria should not be limited to theoretical knowledge and a computer-based test can be used. The examination content should contain three parts - theoretical knowledge, modeling, and quota valuation - to test the students' theoretical knowledge and practical skills.

(6) Correctly and flexibly handle the relationship between teachers, students, teaching materials and media

Usually, the teacher stands next to the platform in class and operates the computer to display one screen after another. The students look at it quietly. The light and shadow on the screen are flashing and colorful, accompanied by pleasant sounds. It is very interesting, but it is flashy and does not receive good teaching results. In multimedia teaching, teachers should consider how to use different teaching methods reasonably to enable students to learn deeper, more and wider knowledge. The whole teaching process should be organized by teachers. The application of multimedia should be gradually introduced under the arrangement of teachers. To make multimedia play an efficient role, it all depends on teachers' control over the adjustment of specific teaching links in teaching. The teaching content and the media chosen are fixed, while the students are diverse. When some students encounter some teaching difficulties or doubts, if they only use multimedia to repeat mechanically, they cannot be different from person to person and cannot be explained in depth, thus the teaching effect is often greatly reduced. At this time, if the teacher's explanation can be interspersed, the students will have new gains due to the difference of the teacher's speed and tone. Therefore, before using multimedia to assist teaching, teachers should make necessary explanations and inspirations so that students know what to see, how to see, what to listen to and how to listen. Under the careful guidance of teachers, teachers should guide students to think, attract students' attention, enable them to actively and actively acquire knowledge from it, fully reflect the leading role of teachers and the main role of students, highlight the auxiliary function of multimedia, and never allow multimedia to simply replace teachers' teaching.

Finally, it must be pointed out that BIM-based "five-in-one" new teaching mode is the need of the times and the necessity of development. It is like a fertile soil and a new bud. It is worth our hard work and careful cultivation. It provides us with an incomparable teaching environment for traditional teaching. We should seize the opportunity of vigorously popularizing information technology in our country, emancipate our minds, open up new ideas, closely combine modern information technology teaching with modern education ideas, and explore more new teaching modes. The "five-in-one" teaching model not only provides the basic paradigm for classroom teaching, but also provides a larger space for teachers' individualized teaching, so as to better embody the teaching idea of "learning as teaching" and truly transform the teaching idea of autonomy, cooperation and inquiry into classroom teaching behavior.

\section{Discussion}

\subsection{Case study}

Four majors are offered in the School of Construction and Engineering at an University: civil engineering, engineering management, construction cost, and municipal engineering. In 2016, 53 students majoring in cost majors were enrolled in Class 1 and 50 in Class 2. A total of 52 engineering management majors were enrolled in Class 1 and 51 in Class 2. To comprehensively accelerate the development of a high-level local applicationoriented environment with distinctive features, the university insists on integrating innovation and entrepreneurship education into the process of talent cultivation. This project is a combination of industry and education, it is BIM-based teaching reform in the course on the measurement and valuation of prefabricated construction as well as the construction of a BIM-based construction cost practice base. The project has helped the school build two BIM laboratories, with each accommodating 60 people, and publish a textbook on the 
measurement and valuation of prefabricated construction. In 2018, the university executed a teaching reform and applied the "five-in-one" teaching mode based on BIM to the four classes, to improve students' hands-on ability and innovativeness.

(1) Application of "five-in-one" teaching mode based on BIM

In the fall semester of 2018 , a contrast test was conducted in the four classes in the School of Construction and Engineering. Construction cost majors enrolled in Class 1 and Class 2 in 2016 used the new textbook on the measurement and valuation of prefabricated construction using the "five-in-one" teaching mode based on BIM. The teacher first taught basic theoretical knowledge in each chapter, and then trained students in chapter-specific, BIM-based BQ item cases spanning 42 class hours. After having taught all cases of the BQ, the teacher trained students on a BIM-based case, which took six class hours. By contrast, Class 1 and Class 2 of engineering management majors enrolled in 2016 used the same textbook in the traditional teaching mode, which took 32 class hours. Having taught the theory, the teacher trained students in the BIM-based case of the BQ and the complete case, which took 16 class hours. Each class had a total of 48 class hours. At the end of the semester, a computer-based test was administered for $120 \mathrm{mins}$, where $40 \%$ of the test related to theoretical knowledge, $40 \%$ to modeling, and $20 \%$ to quota valuation. The scores of students in the four classes were sorted in descending order, as shown in Figure 1. The average scores are shown in Figure 2, and the test completion times were sorted in ascending order as shown in Figure 3.

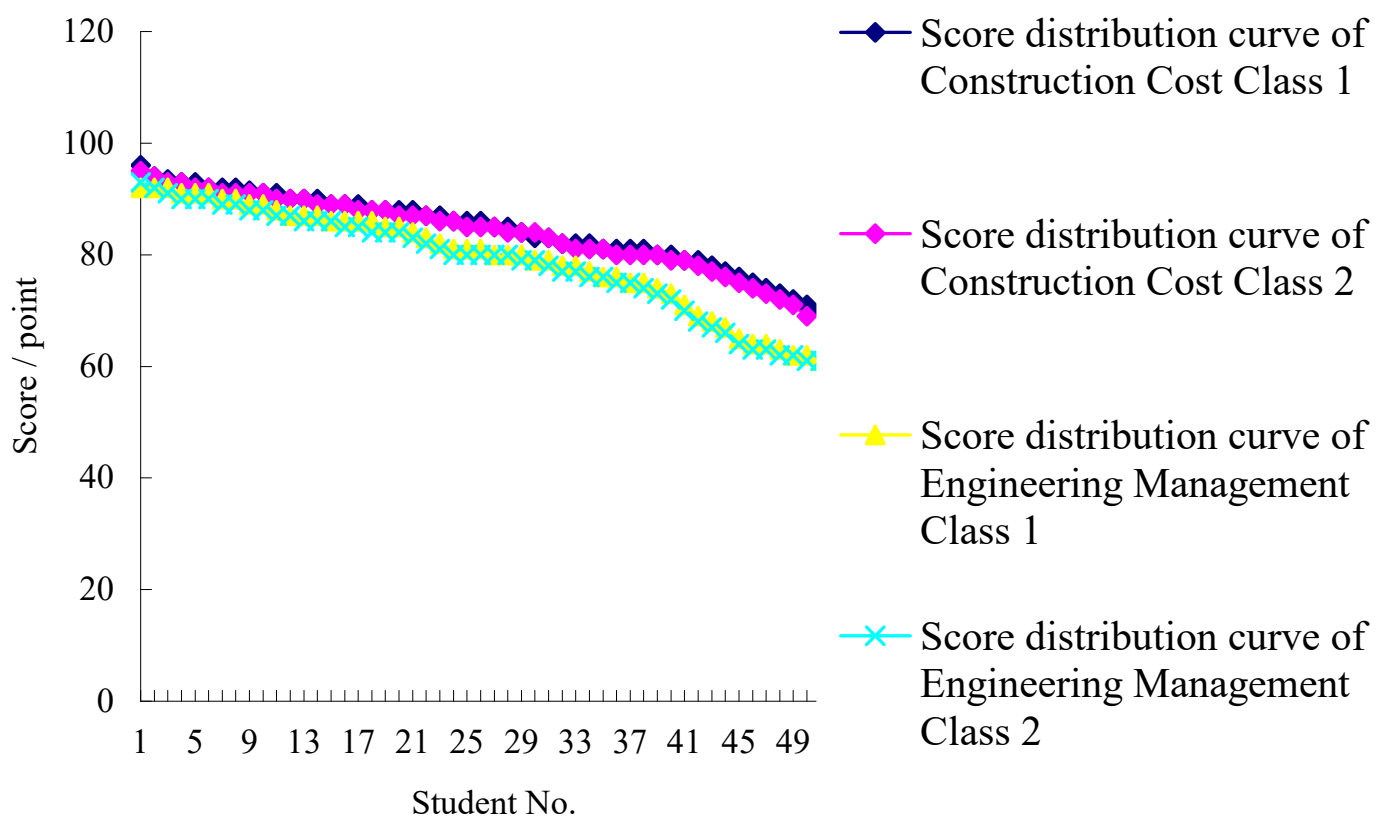

Figure 1. Score distribution curve of students in four classes in descending order 


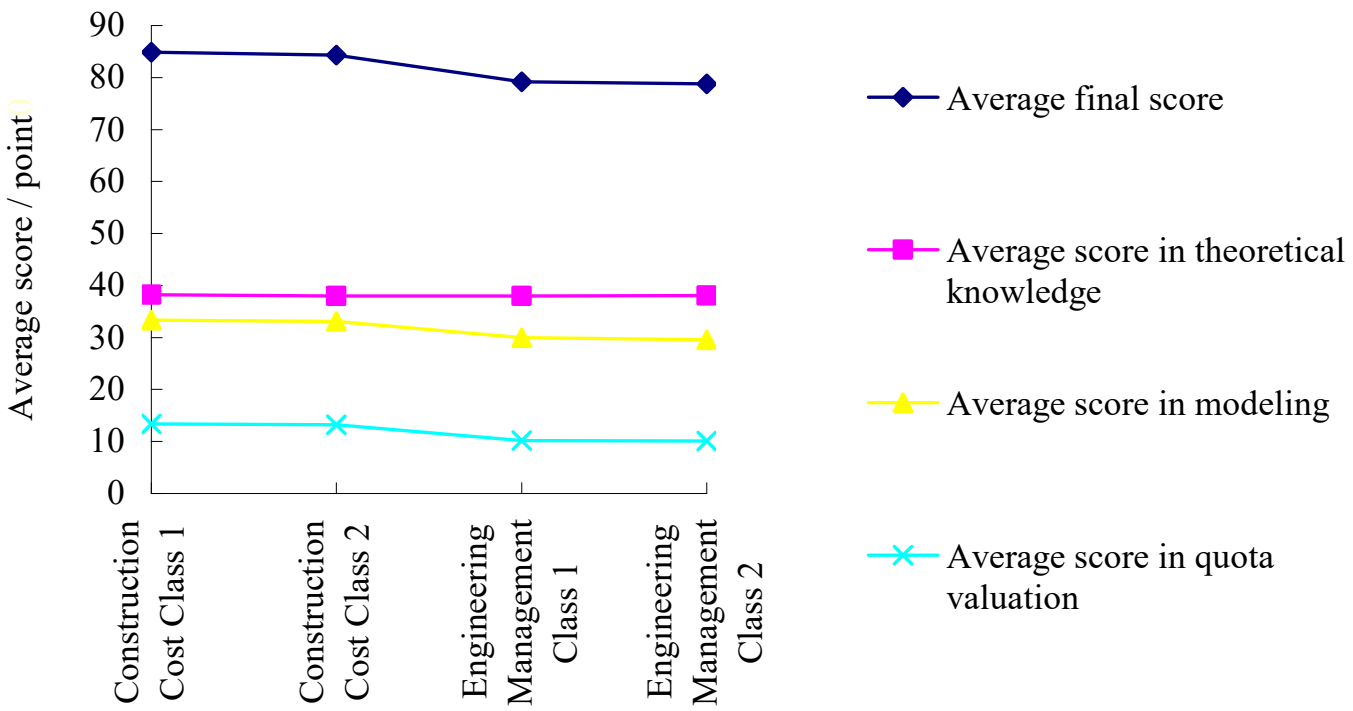

Class name

Figure 2. Average score distribution curve of students in four classes

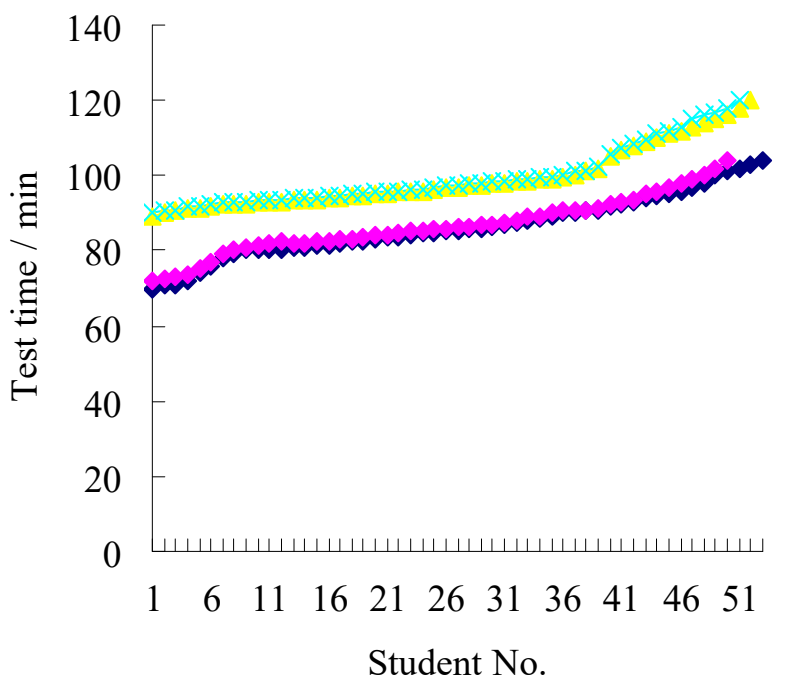
$\longrightarrow$ Test time distribution curve of
Construction Cost Class 1

$\longrightarrow$ Test time distribution curve of Construction Cost Class 2

Test time distribution curve of Engineering Management

Class 1

Test time distribution curve of Engineering Management Class 2

Figure 3. Test time distribution curve of students in four classes in ascending order

(2) Comparative analysis of new and old teaching modes

The new and old modes of teaching were applied to Construction Cost Class 1 and Class 2 as well as Engineering Management Class 1 and Class 2. This produced different effects, and the obtained results were compared and analyzed as follows:

Figures 1 and 2 show that the final scores of Construction Cost Class 1 and Class 2 are apparently higher than those of Engineering Management Class 1 and Class 2. The average score of Construction Cost Class 1 was 84.9 points, that of Construction Cost Class 1 was 84.3 points, that of Engineering Management Class 1 was 78.2 points, and that of Engineering Management Class 2 was 77.8 points. This shows that the new "five-in-one" teaching mode based on BIM outperformed the traditional teaching mode, and increased the scores by $9.13 \%$ at most.

Figure 2 shows that the main reason for the higher final scores of Construction Cost Class 1 and Class 2 than those of Engineering Management Class 1 and Class 2 is that there were differences in their modeling and quota valuation, even though their scores in the theoretical knowledge part were almost identical. The result of modeling directly affected the accuracy of the result of quota valuation. As the average scores of Engineering Management Class 1 and Class 2 in modeling and quota valuation parts were three points lower than those of 
Construction Cost Class 1 and Class 2, the deviation in the results of assessment directly arose from differences in operational skills in modeling.

Further, Figure 3 shows that the final test completion times of Construction Cost Class 1 and Class 2 is clearly shorter than those of Engineering Management Class 1 and Class 2. Specifically, the average completion time of Construction Cost Class 1 was 86.4 mins, that of Construction Cost Class 1 was 86.5 mins, that of Engineering Management Class 1 was 99.5 mins, and that of Engineering Management Class 2 was 99.8 mins. This indicates that the "five-in-one" teaching mode based on BIM sharpened students' practical skills in modeling and improved their proficiency, which saved $13.4 \%$ of time at most.

It is not difficult to find that the "five in one" teaching mode is based on the teaching task of each chapter. the teaching teacher leads the students to learn theoretical knowledge first, then to conduct model building demonstration operation of each chapter, and then the students themselves conduct model building practical exercises to promote each student to master theoretical knowledge. After the practical exercises, the theoretical and practical knowledge was exchanged and discussed, and the corresponding basic theoretical knowledge was further consolidated and reviewed. Through the last two chapters of the whole case system to practice, can be a comprehensive review of all theoretical knowledge of books, so through the "five-in-one" teaching mode, to master the theoretical knowledge of books has a positive contribution.

The teacher's evaluation of the performance of the students in class made it clear that the "five-in-one" teaching mode based on BIM can stimulate students' enthusiasm. The highlight of the traditional mode of teaching is that this teacher-centric mode leads students to passively accept knowledge and learn by rote. This mode is of no benefit to cultivating their core literacy. As theoretical knowledge in the course on the measurement and valuation of prefabricated construction is unintelligible to them, students often feel bored with the course and thus lack enthusiasm. The "five-in-one" teaching mode of "teaching, learning, practice, discussion, and practice" changes the traditional teaching mode. Through clear means of teaching and by employing methods of modern Information Technology, students can become active participants in the teaching process.

\section{Conclusions}

In this paper, we researched the BIM-based practical training course on the measurement and valuation of prefabricated construction and proposed a "five-in-one" teaching mode of "teaching, learning, practice, discussion, and practice". In addition, we proposed adjusting teachers at universities in the relevant department and formulating an improved teaching plan. These measures can allow us to motivate students' interest in learning, organically combine theoretical knowledge with practical teaching, and train students' practical skills. We can thus achieve the goal of developing application-oriented technical personnel.

The proposed teaching mode of the BIM-based practical training course applies and promotes modern Information Technology in teaching construction cost majors, and plays a pioneering role in the application of BIM technology to teaching reform in other specialized courses. The proposed teaching mode provides a theoretical basis for this teaching reform.

Through a comparative analysis of new and old teaching modes applied to four classes in the School of Construction and Engineering at Guangxi University, we found that the BIM-based practical training course on the measurement and valuation of prefabricated construction produces outstanding teaching effects in terms of the results of students' assessments and their acquisition of BIM-based practical skills. Therefore, this method can provide a reference for teaching reform in application-oriented undergraduate institutions in the Guangxi Zhuang Autonomous Region, and even across China.

In short, the five-in-one teaching mode has changed the previous teaching methods. By establishing vivid teaching scenarios and combining theory with practice, students are enabled to actively participate in classroom teaching, changing passive acceptance of knowledge into active acceptance of knowledge, which truly reflects the teacher-led and student-centered role. It not only greatly stimulates students' interest in learning, improves students' learning efficiency, but also enhances students' practical operation function, thus meeting the needs of jobs. The five-in-one teaching mode is not only beneficial to the improvement of students' comprehensive quality, but also beneficial to the improvement of teachers' teaching ability. More importantly, it is beneficial to strengthen the connection between schools and enterprises, and is conducive to the cultivation of skilled and practical talents more suitable for enterprises.

\section{Acknowledgments}

I would like to thank the Ministry of Education for its Cooperative Education Project between Industry and University and Caiwei Junhua Company for its strong support. The project name is BIM-based teaching reform practice and research, and the project number is 201802116004.

\section{Disclosure statement}

No potential conflict of interest was reported by the author. 


\section{References}

Lin, Y.C., Chang, J.X., Su, Y.C. ( 2016). Developing construction defect management system using BIM technology in quality inspection. Journal of Civil Engineering and Management, 22(7):903.

He, R., Luan, Y.Y., Gao, D. (2017). Discussion about Reform of Civil Engineering Course System Based on BIM Talent Training. Journal of Graphics, 1.

Wang, X.P., Cai, P.J., Liu, Y.L., et al. (2017). Student-centered and ability training-oriented curriculum reform in teaching Microcontroller Principles and Interface Techniques. Proceedings of the SPIE, 8.

Mehmet, Y., Vishal, S. (2014). Building Information Modeling (BIM) for Facilities Management - Literature Review and Future Needs. 11th IFIPWG 5.1 International Conference, 7:1-10.

Yang, F.S, Zhang, Z.X., Wang, Y.Q., et al. (2017). Teaching Reform Practice in the Background of Education Internationalization: An Example. DEStech Transactions on Social Science, Education and Human Science.

Liu, D. (2014). Talking about the Teaching Reform of "Construction Engineering Measurement and Valuation" Course for Engineering Cost Major in Higher Vocational Colleges. Education and Teaching Forum, 12.

Fang, S.T., Zhang Y. (2014). Research on Teaching Reform of "Measurement and Valuation of Construction Engineering". Heilongjiang Education, 5.

Wu, G.D, Tang, C.L. (2015). Thinking on BIM Technology Integrating into Engineering Management Teaching in Colleges and Universities. Journal Of Architectural Education In Institutions Of Higher Learning, 4.

Liu, Q. (2017). On the teaching method of measurement and valuation of construction engineering reform. Teaching Forum, 16.

Wang, W. (2016). Research on the Construction of Stereoscopic Practical Teaching System for Engineering Management Specialty. Journal of Higher Education, (1): 167-168.

Fan, J.M., Shao, Y.J., Dou H.P. (2017). Skill-oriented Curriculum Reform and Practice in the Context of Schoolenterprise Cooperation-Taking the Course of "Measurement and Valuation of Construction Engineering" for Engineering Cost Major of Hefei Vocational and Technical College as an Example. Journal of Chaohu University, 3.

Ma, X.R., Zhang, X.L., Tang, W.H. (2015). Innovation and Practice of Characteristic Talents Training System for Engineering Cost Specialty in Higher Vocational Colleges Based on the Construction of Training Bases in Schools. Knowledge Economy, (1):147.

Azhar, S., Khalfan, M., Maqsood, T. (2012). Building information modelling (BIM): now and beyond[J]. Australasian Journal of Construction Economics and Building, 12(4):15-28.

Miettinen, R., Paavola, S. (2014). Beyond the BIM utopia: Approaches to the development and implementation of building information modeling. Automation in Construction, 43 (7):84-91.

Demian, P., Walters, D. (2014). The advantages of information management through building information modelling. Construction Management \& Economics, 32(12): 1153-1165.

Li, M.J. (2017). Construction of "Five-in-One" Practical Teaching Model for Ideological and Political Theory Course. Party Construction and Ideological Education in School, 22.

Wang, W.X. (2018). Reform and Innovation of Economic Law Teaching. Shanxi Education (Higher Education), 6.

Cun, X.E. (2017). An experimental project for the comprehensive design of Multimedia Technology based on the "Five in One" teaching mode. Fujian computer, 2.

Zhou, C.X., He, Z.G., Jia, Y. (2015). Application of CDIO Teaching Mode for Computer Software Courses. 7th International Conference on Information Technology in Medicine and Education (ITME).

Wang, Y.S., Liu, S.Y. (2016). Application of Flipped Classroom Teaching Mode in Experimental Chemistry Courses. University Chemistry, 4.

Qian, P. (2016). Research on College English Teaching Mode based on Task-based Teaching Method and Flip the Classroom Mode. International Technology Management, 7.

Cai, X.P. (2017). Application of Information Technology in Measurement and Valuation of Construction Projects. Science and Technology Economic Market, 9.

Luo, S.L., Cheng, H. (2017). Teaching Reform and Practice of "Measurement and Valuation of Construction Engineering" Course. Zhejiang Architecture, 3.

Zhu, H.G., Yi, C., W.Q., et al. (2015). Application Status and Suggestions of BIM Technology in Civil Engineering Teaching. Education and Teaching Forum, (44):184-185.

First Author is director of the education and training center of Hezhou university and a master's tutor. he is specialized in BIM application technology research. he is currently writing a teaching practice and research paper on the construction of new engineering with five integrated teaching modes. my interests also include artificial intelligence, cybernetics, teaching management, organizational behavior.

Second Author is a laboratory technician in the School of Architecture and Engineering of Hezhou University, specializing in experimental teaching. 